\title{
Daily variations of the refractive index in the south of the Vitim plateau in different seasons of the year
}

\author{
Aryuna Bazarova*, Evgeniy Atutov, Alexander Bazarov, Yuri Bashkuev \\ Institute of Physical Materials Science of the Siberian Branch of the Russian Academy of Science, \\ Buryatia, Russian Federation
}

\begin{abstract}
The urgency of the problem of studying the refractive properties of the troposphere is determined by the increasing rate of use of radio meteorological parameters in the design and operation of GLONASS-GPS and GSM radio-electronic systems in various physical and climatic regions of the Earth, in particular in eastern Russia. Specialists are faced with an urgent need to study the laws governing the propagation of VHF-UHF radio waves taking into account the influence of all layers of the atmosphere as a medium with a variable refractive index. The article presents the calculation of the refractive index $\mathrm{N}$ based on meteorological data of the atmosphericsoil measuring complex, located on the measuring station in the Eravninsky district of the Republic of Buryatia. The dependences of the refractive index on atmospheric pressure, water vapor elasticity, and absolute air temperature are established.
\end{abstract}

The influence of the troposphere on the propagation of ultrashort radio waves is manifested, as is known, in the form of refraction (refraction) of radio waves, reflection of radio waves from layered inhomogeneities of the troposphere, scattering of VHF on turbulent inhomogeneities of the atmosphere, as well as scattering of radio wave energy by hydrometeors (snow, snow, degrees), gases and other impurities in the atmosphere.

The propagation of radio waves is mainly determined by the atmospheric response. It consists in the fact that due to the dielectric inhomogeneity of the atmosphere, electromagnetic waves propagate non-linearly [1]. The dielectric constant of air $\varepsilon$ and the associated refractive index $n(n=\sqrt{\varepsilon})$ can be obtained directly using radio refractometers. However, the latter are rather complicated, expensive, and not readily available for mass measurements. Since the refractive index of the troposphere at the earth's surface $n$ is only three ten-thousandths higher than one, it is considered more convenient to use the so-called refractive index $\mathrm{N}$, which is related to $\mathrm{n}$ by the ratio $N=(n-1) \times 10^{6}$, instead of the refractive index. Thus, the refractive index shows how many parts per million the refractive index is greater than one. Usually $\mathrm{N}$ is a three-digit number. If, for example, $\mathrm{n}=1.000325$ for a normal troposphere at the surface of the earth, then $N$ is expressed by the number 325 . Millionths of the refractive index of air (i.e. units) are called N-units. In what follows, the refractive index will mean the refractive index (refraction) in $\mathrm{N}$-units.

\footnotetext{
${ }^{*}$ Corresponding author: arunabas@mail.ru
} 
With data on atmospheric pressure, temperature and absolute humidity, the refractive index (or refractive index in $\mathrm{N}$-units) can also be calculated using the well-known formula $[2,3]$ :

$$
N=(n-1) \times 10^{6}=\frac{77,6}{T} \times\left(P+\frac{4810 e}{T}\right)
$$

$\mathrm{P}$ - atmospheric pressure, mbar; e - water vapor pressure, mbar; $\mathrm{T}$ - the absolute air temperature, K. For the commonly occurring values of $\mathrm{P}, \mathrm{T}$ and e, formula (1) is considered accurate within $0.5 \%$ over the entire radio wave range at $\lambda \geq 1.3 \mathrm{~cm}$. From formula (1) it follows that with an increase in $\mathrm{P}$ and e increases $\mathrm{N}$, while an increase in $\mathrm{T}$ decreases $\mathrm{N}$.

Meteorological values tend to change with the time of day throughout the year [4]. In this paper, we investigate the behavior of the refractive index depending on the variability of the weather in the vicinity of the village of Sosnovo-Ozerskoe, Eravninsky district of the Republic of Buryatia.

The Eravninsky district, with an area of 25.6 thousand $\mathrm{km}^{2}$, borders in the south-west with Kizhinginsky, in the west with Khorinsky, in the north with the Bauntovsky Evenki districts of Buryatia, in the east and south-east there is a border with the Trans-Baikal Territory. The region is located in an intermountain forest-steppe depression on the southern edge of the Vitim plateau, in the basins of the Uda and Vitim rivers. The main features of the modern earth's surface of the region are represented by the following forms of relief: the ancient Vitim plateau, the Eravninsky intermountain basin, river valleys, along which the large rivers Vitim, Uda, Konda flow. On all sides, the territory of the region is bordered by spurs of large ridges: from the south-east - by the spurs of the Yablonovy ridge, from the south - by the Tsagan-Khurtei ridge, from the west - by the Selenga middle mountains. The highest elevations of the plateau within the region are located north of the middle course of the Zaza River (1269 m).

The climate is sharply continental with little snow, long and frosty winters, and short but warm summers. The amount of precipitation per year is $270-310 \mathrm{~mm}$ per year. The lowest temperature in January drops to minus 35-52 degrees Celsius, while summer temperatures in July rise to 25-40 degrees above zero. The area belongs to the zone of sporadic "permafrost".

Long-term monitoring of atmospheric and soil meteorological parameters is carried out by the atmospheric-soil measuring complex ASMC-007 (Figure 2) [5] at the permafrostecological station of the Institute of General and Experimental Biology (IEEB) of the SB RAS in the Eravninsky depression (Figure 1). Measurements are taken eight times a day every three hours with a conditional beginning at 7:00 am local time, that is, at 7:00, 10:00, 13:00, 16:00, 19:00, 22:00, 01:00, 04:00 and so on. To determine the variations in the refractive index $\mathrm{N}$, we need a series of data on temperature, air humidity and atmospheric pressure. 


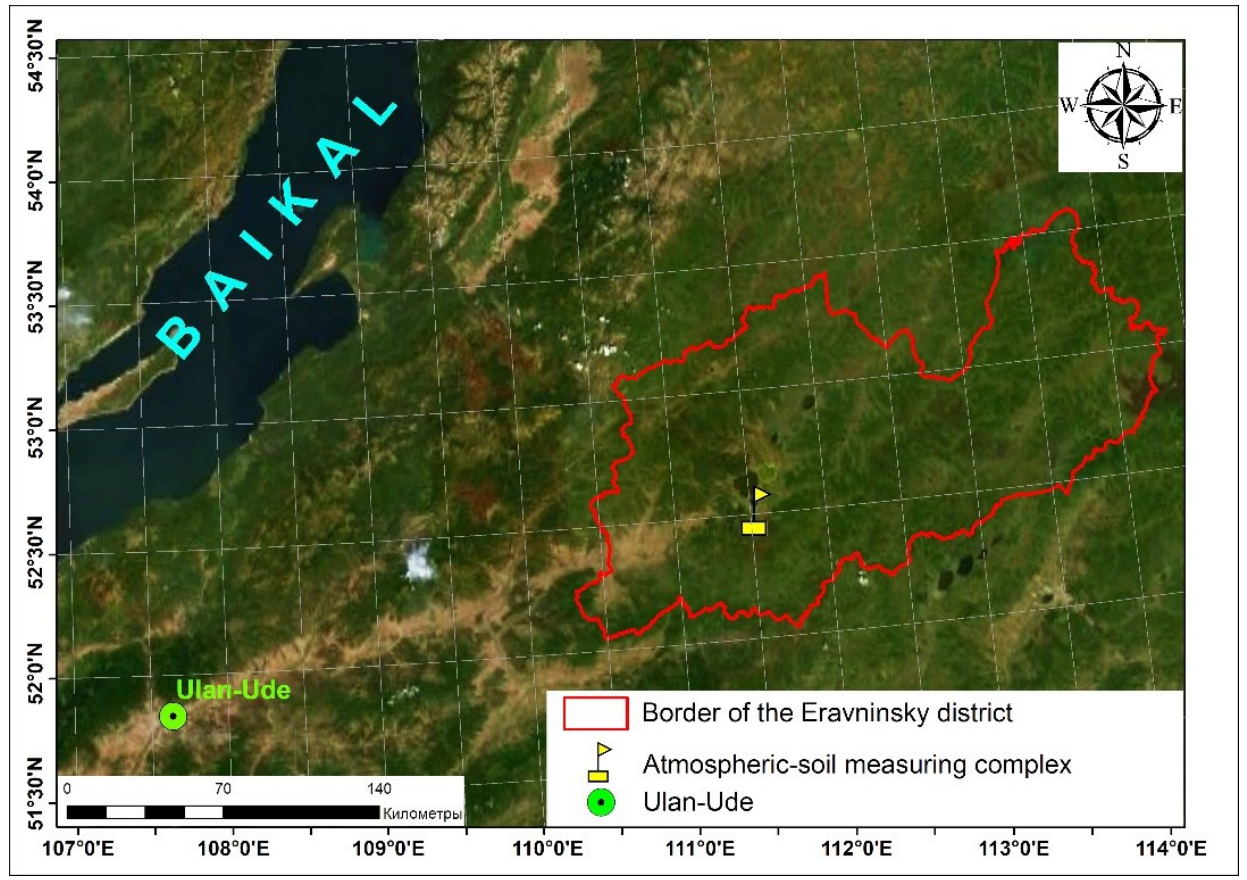

Fig. 1. Measurement point location of the Eravninsky district territory

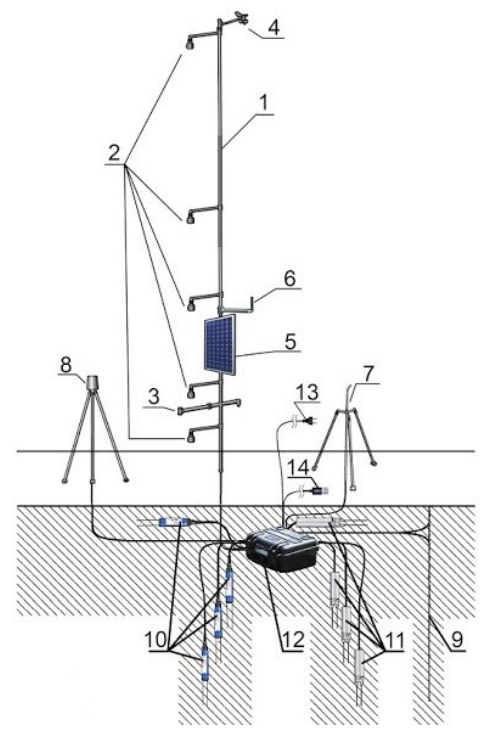

\begin{tabular}{|c|c|c|}
\hline № & Component & Range, error \\
\hline 1 & Mast & $10 \mathrm{~m}$ \\
\hline 2 & $\begin{array}{l}\text { Air temperature and } \\
\text { humidity sensor }\end{array}$ & $\begin{array}{c}-55 \ldots+50^{\circ} \mathrm{C}, \pm 0.3^{\circ} \mathrm{C} \\
0 . . .100 \%, \pm 3.5 \%\end{array}$ \\
\hline 3 & Total solar radiation sensor & $\begin{array}{c}0.2 \ldots 10 \mu \mathrm{m}, \pm 10 \% \\
0-2000 \mathrm{~W} / \mathrm{m}^{2},- \\
55 \ldots+50^{\circ} \mathrm{C}\end{array}$ \\
\hline 4 & $\begin{array}{l}\text { Sensor of wind speed } \\
\text { and direction }\end{array}$ & $\begin{array}{c}0.9 \ldots . .78 \mathrm{~m} / \mathrm{s}, \pm 5 \% \\
0 . . .360^{\circ}, \pm 7 \%\end{array}$ \\
\hline 5 & Solar battery & \\
\hline 6 & GSM antenna & \\
\hline 7 & Snow depth sensor & $0 . . .0 .7 \mathrm{~m}, \pm 0.05 \mathrm{~m}$ \\
\hline 8 & Liquid precipitation sensor & $0 . .1000 \mathrm{~mm} / \mathrm{h}, \pm 5 \%$ \\
\hline 9 & Soil temperature profile sonde & $-55 \ldots+50^{\circ} \mathrm{C}, \pm 0.2^{\circ} \mathrm{C}$ \\
\hline 10 & Soil moisture sensor & $\begin{array}{c}0 . . .100 \% \\
-15 \ldots+50^{\circ} \mathrm{C}\end{array}$ \\
\hline 11 & Water conductivity sensor & $10 \ldots 2 \times 10^{3} \mu \mathrm{S} / \mathrm{cm}, \pm 20 \%$ \\
\hline 12 & $\begin{array}{l}\text { Case with control electronics } \\
\text { and air pressure sensor }\end{array}$ & $\begin{array}{c}500 \ldots 1150 \mathrm{hPa}, \pm 10 \mathrm{hPa} \\
375 \ldots 862 \mathrm{~mm} \mathrm{Hg}, 7,5 \\
\mathrm{~mm} \mathrm{Hg}\end{array}$ \\
\hline 13 & Redundant power supply & $220 \mathrm{~V}$ \\
\hline 14 & USB & \\
\hline
\end{tabular}

Fig. 2. ASMC scheme. The numbering of components in the table coincides with the designations on the scheme

Dual air temperature and humidity sensors located on a 10-meter mast at heights of 1,2 , 4, 6 and $10 \mathrm{~m}$ are indicated in the diagram as (2). The atmospheric pressure sensor is located in the case (12). To use this data, let's convert millimeters of mercury to millibars, degrees Celsius to Kelvin, percent of air humidity in millibars of water vapor pressure. Let us 
compare the behavior of the refractive index $\mathrm{N}$ on the coldest day on January 22, 2016 and on the hottest day on July 9 (Figure 3, a, b) at a height of 1 and 10 meters.

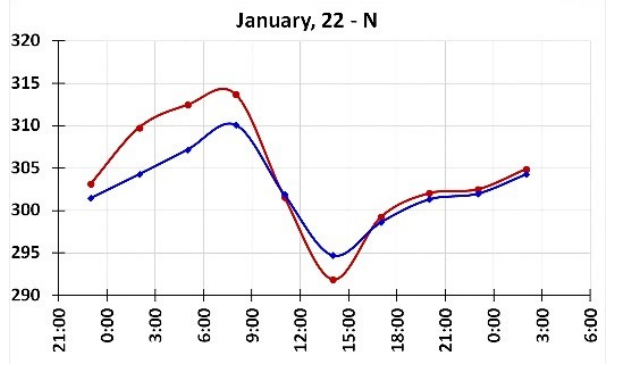

$\rightarrow-1 \mathrm{~m} \rightarrow 10 \mathrm{~m}$

a)

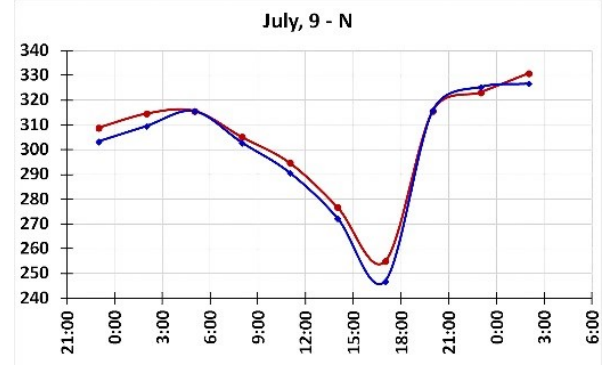

b)

Fig. 3. Refractive index variations N: a) January 22, b) June 9, 2016

The abscissa shows the time in hours, starting with the last measurement of the previous day and ending with the first measurement for the next day. It should be noted that in graph b) the ordinate axis is more stretched, which indicates that on summer days the amplitude of the refractive index $\mathrm{N}$ variations during the day is greater than in winter. In winter, during the daytime hours (11:00-16:00), the $\mathrm{N}$ inversion occurs: the value of $1 \mathrm{~m}$ becomes less than $10 \mathrm{~m}$. On June 9, such a change does not occur, although this is possible due to increased turbulence on the considered day. The amplitude of winter variations is $22 \mathrm{~N}$-units, and of summer $-60 \mathrm{~N}$-units.

Figure 4 shows the graphs of meteorological data used to calculate $\mathrm{N}$ in formula (1) for the same day.

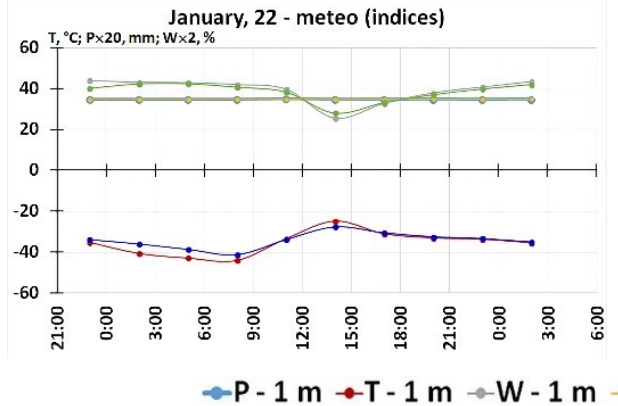

a)

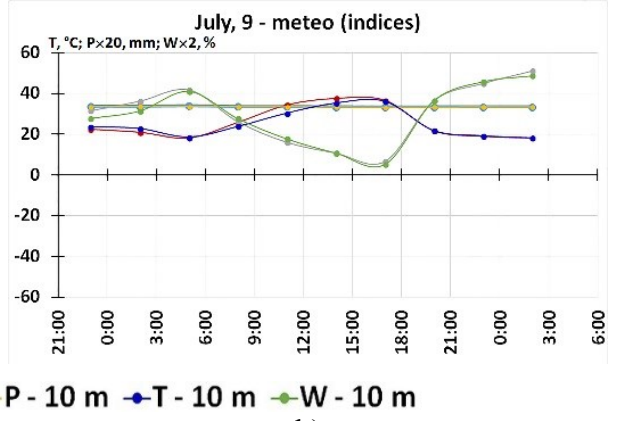

b)

Fig. 4. Temperature, air humidity and atmospheric pressure variations: a) January 22, b) June 9, 2016

In order for all the graphs to fit on one diagram, we had to divide the $\mathrm{P}$ values by 20 , and $\mathrm{W}$ by 2 . That is, if we see the atmospheric pressure value on the graph at 34.5 , then the real reading is $690 \mathrm{~mm} \mathrm{Hg}$. Art., and the indicator humidity 40 on the graph means air humidity $80 \%$. Comparison of Figures 3 and 4 shows that in the Eravna Basin, variations in the refractive index $\mathrm{N}$ are more influenced by air temperature and humidity than atmospheric pressure, which is kept practically at the same level. The greater amplitude of daily fluctuations in $\mathrm{N}$ in summer is probably explained by sharper fluctuations in air humidity.

The results of our measurements coincide with the conclusions of N.T. Gomoboev and C.T. Tsydypov [2], who conducted a study of the value of the refractive index of air near the Earth's surface in Transbaikalia based on the materials of three ground stations of the hydrometeorological service network for 5 years (1958-1962). The stations were located in 
different physical and geographical conditions: Ulan-Ude and Barguzin - far from large bodies of water, Ust-Barguzin - on the shore of the lake. Baikal:

1. Daily changes in $N$ mainly depend on humidity and air temperature, since the pressure changes insignificantly during the day.

2. According to the results of calculations of the daily rate $\mathrm{N}$ is simple with one maximum and one minimum. In winter and autumn, everywhere the maximum occurs in the morning hours (6 or 7), in spring and summer at some points - at $1 \mathrm{am}$, and at others - at 6 or $7 \mathrm{am}$. The minimum is observed everywhere and in all seasons in the afternoon (13-15 hours).

3. According to the amplitudes of daily changes in $\mathrm{N}$, calculated from long-term data, it can be seen that the largest amplitudes occur in summer, and the smallest ones - in winter.

Based on the results of meteorological measurements and calculations of the refractive index $N$, the following conclusions can be drawn.

1. The refractive index $\mathrm{N}$ in the surface layer of the atmosphere has pronounced daily fluctuations

2. The diurnal variations of the refractive index $\mathrm{N}$ in the south of the Vitim plateau are determined to a greater extent by variations in air temperature and humidity than by atmospheric pressure.

3. In the daytime, an inversion of $\mathrm{N}$ with altitude is observed in the absence of atmospheric turbulence.

The work was carried out within the framework of the budget project 0336-2019-0006 "Propagation of radio waves in inhomogeneous impedance channels".

\section{References}

1. A.O. Adelakun, J.S. Ojo, O.V. Edward, Adv. Sp. Res. 65, 9, 2203-2215 (2020)

2. N.T. Gomboev, C.T. Tsydypov, Troposphere refractive properties of continental regions (Nauka, Novosibirsk, 1985)

3. The radio refractive index: its formula and refractivity data. Recommendation ITU-R P.453-12 (International Telecommunication Union, Geneva, 2016)

4. N. Yusuf, O.E. Ekpe, R.S. Said, B.G. Ayantunji, A.E. Umahi, Meteorol. Atmos. Phys. 132, 3, 327-340 (2020)

5. A.V. Bazarov, N.B. Badmaev, S.A. Kurakov, B-M.N. Gonchikov., Russ. Meteorol. Hydrol. 43, 4, 271-275 (2018) 